\title{
Friedreich's Ataxia in the South of Italy : A Clinical and Biochemical Survey of 23 Patients
}

\author{
G. CAmpanella, A. Filla, F. DE FAlCo, D. MANSi, A. DURivage, A. Barbeau
}

SUMMARY: We report a clinical and biochemical survey of 23 patients with Friedreich's ataxia from southern Italy. They were studied clinically and by means of a clinical rating scale devised by us (Inherited Ataxias Clinical Rating Scale). Laboratory tests, based on the Quebec Cooperative Study, were also performed on our patients. No major clinical or biochemical differences were found between Italian and Canadian patients. Investigation of CSF monoamine metabolites showed that $H V A$ decreased after probenecid and metoclopramide loading.

RÉSUMÉ: Nous présentons une étude sur 23 patients d'une région du sud de l'ltalie, atteints de l'ataxie de Friedreich. Ils ontété étudiés, du point de vue clinique, à l'aide d'une échelle d'évaluation clinique comprenant 13 items. Nous avons élaboré cette échelle en vue de l'évaluation des dégénérescences spino-cérébelleuses. Une batterie de tests de laboratoire a été effectuée chez nos patients, en parallèle aux investigations de l'Étude Coopérative Québécoise sur l'Ataxie de Friedreich. Nous n'avons pas trouvé de différences majeures entre les patients italiens et canadiens. Sont aussi présentés des résultats nouveaux sur les métabolites des monoamines dans le LCR.

From the Department of Neurology, Second School of Medicine. University of Naples (Italy) and Department of Neurobiology, Clinical Research Institute of Montreal.

Reprint requests for the complete supplement on Friedreich's ataxia (Phase three) to: Dr. André Barbeau, Clinical Research Institute of Montreal, 110 Pine Avenue West, Montreal, Quebec, Canada, H2W 1 R7.
The Quebec Cooperative Study of Friedreich's ataxia has stimulated investigations into this disease. In a preceding report we studied the diffusion of inherited spino-cerebellar ataxias (ISCA) in our region of the south of Italy, Campania (Filla et al, 1980a). We stated that the mean prevalence could be calculated as $1 \mathrm{x}$ $10_{+}^{5}$ in a population of about 5 million. This prevalence is close to that found by Skre (1975) in Western Norway and by Gudmundsson (1969) in Iceland. Globally we found 138 cases of ISCA, $61(44 \%)$ of which were Friedreich's ataxia. Of these 61 patients, 23 were available for a more complete survey adopting the same criteria as the Canadian authors. Furthermore, we have proposed a scale for the clinical evaluation of ataxic subjects, based on clinical experience with 56 patients (De Falco et al, 1979). Here we report the results of this survey and compare our clinical and laboratory data with the Canadian patients. Such comparisons are an essential part of the scientific process to rule-out "isolate" effects.

\section{PATIENTS AND METHODS}

The 23 patients were carefully selected; those without the obligatory signs for Friedreich's ataxia as reported by Barbeau (1976a) were discarded. All patients were hospitalized in the Department of Neurology of the Second School of Medicine of Naples and they were subsequently followed as outpatients. A number of parents and kindreds of our patients were visited and Friedreich's ataxia was found only in a few. The parents were all normal.

All the patients were evaluated with our clinical rating scale for inherited spino-cerebellar syndromes (IACRS) (De Falco et al, 1979). Table 1 shows the 13 items of this scale. The score is specified for each item.

We also quantified the clinical involvement in our patients by using a simple scale which measures the disability and progression of the illness (Inherited Ataxias Progression Scale, IAPS):

Stage I: Asymptomatic patient, detected among the siblings or offsprings of a known case of inherited spino-cerebellar ataxia (ISCA).

Stage II: ISCA symptoms present, but mild. The patient was capable of leading an independent life, but work activities were restricted.

Stage III:ISCA symptoms were completely developed; the patient needed constant care and cannot work.

Stage IV: The patient was confined to bed or a wheelchair unless aided.

Furthermore, our patients were evaluated with a clinical disability scale, NUDS (Northwestern University Disability Scale, Canter et al, 1961), and by three manual ability tests: 1. a modified peg-board test, where the patient must place up to 24 test-tubes in a rack within $60 \mathrm{sec} ; 2$. a simple puzzle depicting a little sailor composed of 8 wooden pieces (after learning, time in sec); 3 . an automatic counter, which the patient held in his hand pushing down the lever as fast as possible for $10 \mathrm{sec}$. All three tests were performed with each hand. Finally, three clinical signs of general brain damage, were sought-for: snout reflex, palmomental reflex, and grasp reflex (Ajuriaguerra et al, 1963; Pearce, 1974).

The following laboratory tests were performed: serum and urine glucose, glucose tolerance test (GTT), serum 
TABLE 1

Inherited Ataxias Clinical Rating Scale (IACRS)

For all items the score $0=$ normal or absent.

1. SPEECH
1 =slowed and/or irregular
$2=$ staccato and/or explosive
$3=$ not understandable

2. INTENTION TREMOR (tested with a glass filled with water to $1 \mathrm{~cm}$ from the top, both hands. were tested)

1 =the patient takes the glass to his mouth with tremor, but without spilling any water

$2=$ marked tremor, water is spilt

3 =manoeuvre impossible

3. FINGER-TO-NOSE TEST (right and left arms)

1 =slight dysmetria, but well centered

2 =marked dysmetria (the patient does not center the target)

4. HEEL-TO-KNEE TEST (right and left legs)

(score as for finger-to-nose test)

5. ATAXIA OF GAIT (without shoes)

I =gait possible without support, but with disbalance

2 =gait possible, but sometimes needing support

3 =gait possible only with constant support

4 =gait impossible

6. ROMBERG TEST (observed for 30 seconds)

0 =without swaying, eyes-closed and head in extension

1 =without swaying, but only with eyes open and head straight

2 =swaying with eyes open and head straight

3 =manoeuvre impossible

7. NYSTAGMUS

$1=$ evoked (in vertical and/or lateral gaze vs. right and/or left)

2 =spontaneous (if present, a rotatory component should be mentioned)

8. ARM-PULLING TEST (STEWART-HOLMES TEST, right and left arms)

1 =present (but without the fist hitting the thorax)

2 =marked (fist hitting the thorax)

9. HYPERTONIA

1 =present in lower limbs only

2 =present in upper and lower limbs

10. HYPOTONIA (score as for hypertonia)

11. DEEP TENDON REFLEXES INCREASE IN UPPER LIMBS (right and left) 1 =slight increase

2 =very brisk (polykinetic and/or presence of clonus)

12. DEEP TENDON REFLEXES INCREASE IN LOWER LIMBS (right and left) (score as for upper limbs)

13. DEEP TENDON REFLEXES DECREASE IN UPPER LIMBS (right and left) 1 =reduced

2 =absent

14. DEEP TENDON REFLEXES DECREASE IN LOWER LIMBS (right and left) (score as for upper limbs)

15. BABINSKI SIGN (mention should be made if the answer is right, left or bilateral) $1=$ no response, from the big toe

2 =Babinski

16. VIBRATORY SENSE (at styloid apophysis of the ulnar bone, knee cap, and external malleolus)

$1=$ decreased at lower limb joints (under 11 seconds, with a $128 \mathrm{cps}$ tuning-fork)

2 =decreased at upper and lower limbs

$3=$ absent at lower limbs

4 =absent at upper and lower limbs

MAXIMUM TOTAL SCORE $=42$ lactate dehydrogenase (LDH) and $\alpha$ hydroxy-butyric-dehydrogenase (HB $\mathrm{DH})$, total and conjugated bilirubin, serum cholesterol and triglycerides, serum creatinephosphokinase (CPK) and aldolase, serum ceruloplasmin, chest and spine $\mathrm{X}$-rays, electrocardiogram (ECG), vectocardiogram (VCG), echocardiogram (EchoCG), electroencephalogram (EEG), ophthalmologic examination. Cerebrospinal fluid (CSF) homovanillic (HVA) and 5hydroxy-indoleacetic (5-HIAA) acids were determined according to the technique of Korf et al (1971). Probenecid loading were performed according to a scheme proposed by us (Carrieri et al, 1976).

\section{Neurophysiological study (Prof.}

Caruso, Drs. Santoro and Perretti)

Conventional electromyography was performed on brachial biceps, anterior tibial and abductor digiti minimi muscles. Motor conduction velocity was measured using the standard technique in the median and posterior tibial nerves. Sensory velocity was orthodromically determined in the median and posterior tibial nerves using Buchthal and Rosenflack's method (1966).

\section{RESULTS}

Genetic and general clinical data

Genetic data on our Friedreich's ataxia patients are reported in Table 2, general clinical data in Table 3.

\section{Clinical rating scales}

The data obtained by testing our 23 patients with our clinical rating scale (IACRS) are reported in fig. 1. We divided our patients into three age groups, the first from 11 to 20 , the second from 21 to 30 , the third from 31 to 40 . In fig. 1 the clinical data in the three age groups are compared with the same data arranged dividing the patients in four stages of illness, according to our IAPS scale.

It was evident that not all items progressed regularly with age. Some symptoms such as absence of deep tendon reflexes, Babinski sign, decrease of vibratory sense, and dysmetria of finger-to-nose test, appeared early and were present during the course of the illness. Other signs, such as dysarthria and gait ataxia, showed a 

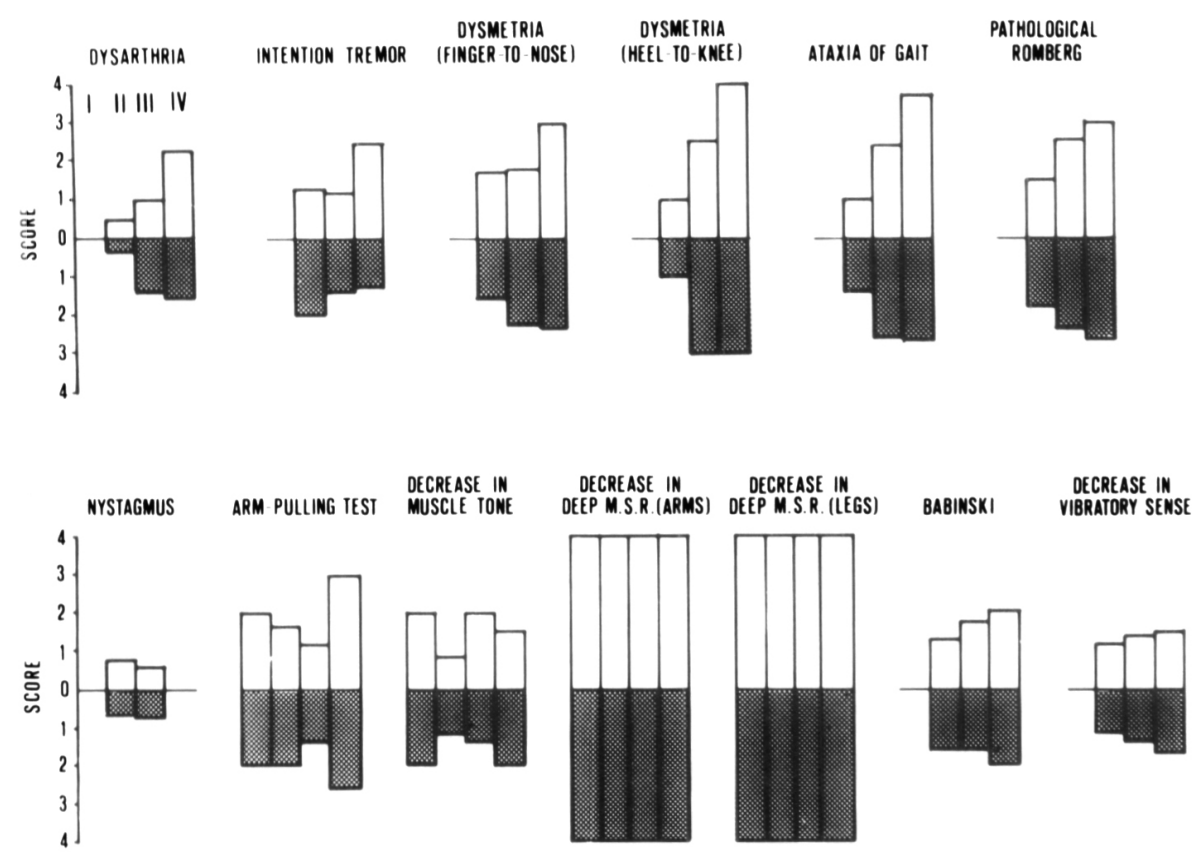

Figure 1 - Inherited Ataxias Clinical Rating Scale (IACRS). See Table 1. Scores of items $1,3,4,5,6,7,8,10,13,14,15,16$ in the 23 Friedreich's ataxia patients. Items $2,9,11$ and 12 were not considered because they were equal to 0 . The figure shows a comparison between the scores when patients are grouped in four stages of illness according to IAPS (white bars; stage II $=7$ patients; stage III $=6$ patients; stage IV $=10$ patients) and the scores when patients are grouped in three age groups (black bars; group $11=11-20$ years, 9 patients; group III $=21-30$ years, 9 patients; group IV $=31-40$ years, 5 patients). Each bar represents the mean score; when an item was investigated bilaterally (arms or legs) the bar represents the mean sum. All scores were corrected, bringing maximum score to 4.

TABLE 2

Genetic Data

\begin{tabular}{ll} 
Relationship & $\begin{array}{l}14 \text { unrelated; } 3 \text { pairs and } 1 \text { triad } \\
\text { of siblings }\end{array}$ \\
Family cases & $10=43 \%$ (5 Kindreds) \\
Sporadic cases & $13=57 \%$ \\
Evidence for recessive inheritance & all cases \\
Parental consanguinity & 4 families (4 patients) $=22 \%$ \\
Suspect Friedreich's ataxia in ascendants & 2 families $=11 \%$ \\
Family pes cavus & 2 fathers and 1 mother \\
Familial diabetes & 6 families $=33 \%$ \\
\hline
\end{tabular}

clear worsening from one age group to the next and from one stage to the next. Muscle weakness in the lower limbs followed the same progression; this is not reported in the IACRS because of its doubtful objectivity. Nystagmus was a minor symptom in Friedreich's ataxia, being often absent in the advanced cases. It should be noted that hypotonia seemed to decrease slightly in the older patients. This was possibly due to a decrease in articular mobility.
Table 4 shows the age range, and IACRS and NUDS scores found in Friedreich's ataxia patients subdivided according to IAPS severity stages. Two subjects at stage I were not reported in this study. IACRS total score ranges from 18 to 35 , thus at the onset of the disease the score was already quite high. On the contrary, the NUDS score, which showed the degree of disability, was sometimes close to the normal level $(=50)$ in the younger patients. We found a signifi- cant correlation between age and IACRS total score $(r=0.6987 ; \mathrm{p}<$ 0.001 ).

Table 5 shows the percentage of pathological signs and symptoms in our patients when examined for the first time. Intention tremor, in contrast with other inherited ataxias, was absent in Friedreich's ataxia.

\section{Manual ability tests and other clinical signs}

The result obtained with the "pegboard", puzzle and automatic counter tests are reported in Table 6 . These results are compared with those obtained in a group of normal controls, in a group of patients with Parkinson's disease and in a group of patients with Huntington's chorea. The puzzle test was excluded from the evaluation of Huntington's chorea because of deterioration and impairment of learning in these patients. Manual ability was clearly reduced in the three groups of patients. In particular, manual performance of Friedreich's ataxia patients was worse for "peg-board" and automatic counter than for the puzzle, while Parkinsonian patients did the puzzle more slowly than the other two tests (partial test for akinesia).

Finally, Table 7 reports the results on the snout, the palmomental, and the grasp reflexes. The snout reflex, much more frequent in Parkinson's disease and Huntington's chorea, was present in $22 \%$ of patients with Friedreich's ataxia. This incidence was probably age related. The palmomental reflex was a rare feature in both Friedreich's ataxia and Huntington's chorea, while the grasp reflex was absent in all these patients. According to Demeurisse et al (1979) the incidence of the palmo-mental reflex also increases with age.

\section{Biochemical findings}

In all 23 patients, serum glucose and GTT were determined. Three showed clinical diabetes (13\%), and six chemical diabetes (26\%). LDH, measured on various occasions, was abnormally high only in two brothers. HBDH was normal in all our patients. CPK was slightly increased only in one of the two brothers with high LDH. Aldolase and ceruloplasmin were always within normal limits. 
TABLE 3

General Clinical Data

\begin{tabular}{llll}
\hline Sex & M & 12 & $52 \%$ \\
& $\mathrm{~F}$ & 11 & $48 \%$ \\
Age of onset & $\mathrm{M}$ & $12.83 \pm 1.27$ \\
& $\mathrm{~F}$ & $12.30 \pm 1.20$ \\
Duration of disease & Both sexes & $12.59 \pm 0.86$ \\
at time of study & $\mathrm{M}$ & $12.41 \pm 2.14$ \\
& $\mathrm{~F}$ & $10.80 \pm 1.87$ \\
Mean age at time of exam & Both sexes & $11.68 \pm 1.42$ \\
& $\mathrm{M}$ & $25.25 \pm 2.23$ \\
& $\mathrm{~F}$ & $24.73 \pm 2.24$ \\
\hline
\end{tabular}

TABLE 4

$I A C R S$ and NUDS scales of Friedreich's ataxia patients subdivided according to IAPS severity stages

\begin{tabular}{lcccc}
\hline $\begin{array}{l}\text { IAPS } \\
\text { stage }\end{array}$ & $\begin{array}{c}\text { No. of } \\
\text { patients }\end{array}$ & Age $\left(^{*}\right)$ & $\begin{array}{c}\text { IACRS }\left(^{*}\right) \\
\text { (total score) }\end{array}$ & $\begin{array}{c}\text { NUD (*) } \\
\text { (total score) }\end{array}$ \\
\hline II & 7 & $16-25(19)$ & $18-26(22)$ & $47-35(43)$ \\
III & 6 & $16-27(21)$ & $24-28(26)$ & $46-33(36)$ \\
IV & 10 & $18-40(29)$ & $27-35(31)$ & $36-16(28)$ \\
\hline
\end{tabular}

(*) Range - In brackets the mean value

TABLE 5

Neurological Signs and Symptoms at First Examination

\section{Item of IACRS}

5 Ataxia of gait

$100 \%$

6 Pathological Romberg test

$100 \%$

3 - 4 Dysmetria

2 Intention tremor

1 Dysarthria

$100 \%$

0

14 Areflexia in lower limbs

$91 \%$

$100 \%$

13 Areflexia in upper limbs

$100 \%$

- Muscle weakness of lower limbs

$83 \%$

10 Hypotonia of lower limbs

$86 \%$

8 Pathological arm-pulling test

$83 \%$

is Babinski sign (1 or 2)

$100 \%$

16 Vibratory sense abolished

$100 \%$ or diminished

- Pes cavus

$96 \%$

(unilateral in

2 patients)

- Scoliosis $>10^{\circ}$

$91 \%$

7 Nystagmus
Cholesterol and triglycerides were determined in 20 patients: cholesterol was above $240 \mathrm{mg} / \mathrm{dl}$ only in one patient, triglycerides were above 160 $\mathrm{mg} / \mathrm{dl}$ in another. The mean value was $166.5 \pm 7.4$ for cholesterol and $94.5 \pm$ 6.2 for triglycerides. The cholesterol level was the same as in a normal population of southern Italy $(M+F$, age $20-29$ ), while triglycerides were significantly increased $(\mathrm{p}<0.025)$ (Filla et al, 1980b).

Total and unconjugated bilirubin were higher than normal values in 4 out of 20 patients $(20 \%)$. One had a history of repeated episodes of jaundice and a bilirubin level constantly above $2 \mathrm{mg} \%$; in the other three the bilirubin increase was mild without clinical manifestations. Three of these 4 patients had chemical diabetes.

The levels of CSF HVA and 5HIAA in our patients are reported in Table 8 . We studied the monoamine metabolites in basal conditions and after loading with probenecid plus metoclopramide. This technique is reported in detail in a previous paper (Carrieri et al, 1976). While probenecid blocks the clearance of $\mathrm{HVA}$ and 5-HIAA from CSF, metoclopramide selectively stimulates DA turnover. In Table 6 the data obtained from Friedreich's ataxia patients are compared with those from two groups of patients with Parkinson's disease and Huntington's chorea. Basal HVA is reduced, but not significantly so in Friedreich's ataxia. Treatment with probenecid plus metoclopramide also shows that DA turnover is significantly reduced in Friedreich's ataxia.

\section{Cardiological investigations}

ECG was performed in 20 patients, EchoCG in 18, and VCG in 9. A pathological ECG picture was found in 15 patients (75\%), while EchoCG was abnormal in 9 patients $(50 \%)$ and VCG in 5 patients $(55 \%)$. The complete results of the cardiological investigations will be reported in a subsequent paper.

\section{Neurophysiological investigations}

EEG was performed in 16 patients. Eleven showed some abnormalities: 1 . irregular background rhythms were present in 11 patients; 2 . slow rhythms were present in 8 of these 11 patients. 
TABLE 6

Manual Ability Tests in.Friedreich's Ataxia and Other Degnerative Diseases

\begin{tabular}{lccccc}
\hline & $\begin{array}{c}\text { No. of } \\
\text { Subjects }\end{array}$ & $\begin{array}{c}\text { Mean } \\
\text { Age }\end{array}$ & $\begin{array}{c}\text { Peg Board } \\
\text { (no. of test-tubes } \\
\text { per 60 sec) }\end{array}$ & $\begin{array}{c}\text { Puzzle } \\
\text { (time in sec) }\end{array}$ & $\begin{array}{c}\text { Automatic Counter } \\
\text { (counts per 10 sec) }\end{array}$ \\
\hline $\begin{array}{l}\text { NORMAL CONTROLS } \\
\text { right hand } \\
\text { left hand }\end{array}$ & 17 & 26 & 50 & 16 & 46 \\
$\begin{array}{l}\text { FREIDREICH'S ATAXIA } \\
\text { right hand } \\
\text { left hand }\end{array}$ & 18 & 22 & 46 & 18 & 43 \\
$\begin{array}{l}\text { PARKINSON'S DISEASE } \\
\text { right hand } \\
\text { left hand }\end{array}$ & 18 & 61 & 18 & 36 & 22 \\
$\begin{array}{l}\text { HUNTINGTON'S CHOREA } \\
\text { right hand }\end{array}$ & 14 & 48 & 26 & 39 & 21 \\
left hand & & & 21 & 57 & 29 \\
\hline
\end{tabular}

TABLE 7

Signs of General Brain Damage

\begin{tabular}{lccccc}
\hline & $\begin{array}{c}\text { No. of } \\
\text { Patients }\end{array}$ & $\begin{array}{c}\text { Mean } \\
\text { Age }\end{array}$ & $\begin{array}{c}\text { Snout } \\
\text { Reflex }\end{array}$ & $\begin{array}{c}\text { Palmo-Mental } \\
\text { Reflex }\end{array}$ & $\begin{array}{c}\text { Grasp } \\
\text { Reflex }\end{array}$ \\
\hline Friedreich's ataxia & 23 & 25 & $5^{*}(22 \%)$ & $1^{*}$ & 0 \\
Parkinson's disease & 18 & 61 & $17^{*}(94 \%)$ & $16^{*}$ & $1^{*}$ \\
Huntington's chorea & 13 & 48 & $9^{*}(70 \%)$ & $3^{*}$ & 0 \\
\hline
\end{tabular}

- No. of patients with a positive reflex

TABLE 8

CSF HVA and 5-HIAA

\begin{tabular}{|c|c|c|c|c|c|c|c|c|c|}
\hline & & \multicolumn{2}{|c|}{ BASAL LEVELS } & \multicolumn{6}{|c|}{ AFTER PROBENECID + METOCLOPRAMIDE } \\
\hline & & $\begin{array}{c}\text { No. of } \\
\text { Patients }\end{array}$ & Age* $^{*}$ & HVA* & 5-HIAA* & $\begin{array}{l}\text { No. of } \\
\text { Patients }\end{array}$ & Age* $^{*}$ & HVA* & 5-HIAA* \\
\hline 1 & Normal Controls & 9 & $38 \pm 5$ & $28.3 \pm 0.8$ & $45.4 \pm 6.3$ & 8 & $33 \pm 6$ & $303 \pm 57$ & $229 \pm 24$ \\
\hline II & Friedreich's ataxia & 9 & $25 \pm 2$ & $12.8 \pm 3.3$ & $28.5 \pm 6.9$ & 5 & $19 \pm 2$ & $150 \pm 35$ & $226 \pm 50$ \\
\hline III & I Parkinson's disease & - & - & - & - & 16 & $58 \pm 2$ & $143 \pm 25$ & $169 \pm 22$ \\
\hline IV & Huntington's chorea & 7 & $52 \pm 4$ & $6.9 \pm 2.5$ & $34.5 \pm 2.5$ & 14 & $45 \pm 3$ & $128 \pm 24$ & $163 \pm 26$ \\
\hline
\end{tabular}

Mean \pm S.E.

Statistical analysis was performed by means of analysis of variance and Duncan's test modified by Kramer. These significant differences were found:

Basal HVA: groups I - IV, $p<0.01$

HVA after probenecid:

groups I - II, $\mathrm{p}<0.05$

I - III and I - IV , p $<0.01$ 
Only in one patient were there paroxysmal rhythms of deep median origin.

Nineteen Friedreich's ataxia patients underwent electromyography, motor conduction velocity and sensory conduction velocity. The electromyographic results showed a moderate to severe loss of motor units with a significant increase in mean potential duration and incidence of polyphasics in about $60 \%$ of subjects. Spontaneous activity of short duration was rarely observed. Regarding conduction velocity along motor and sensory fibers in the median and posterior tibial nerves, the main pathological features found in our patients were: 1 . increase of distal conduction time to muscles; 2 . moderate slowing of motor and sensory velocity; 3 . severe amplitude reduction of sensory orthodromically evoked responses (Caruso et al, 1980).

\section{DISCUSSION}

Our study constitutes a survey of 23 patients with Friedreich's ataxia from a region of southern Italy, mainly of clinical and biochemical data. We compared these data with those from Canadian patients, extensively studied in the Quebec Cooperative Study on Friedreich's ataxia. Our patients all belonged to the "typical" cases of Friedreich's ataxia, group Ia of Geoffroy et al (1976).

Genetic data, in our patients, are similar to those found in the Canadian patients. The ratio between family cases and sporadic cases is 0.80 in Italian patients and 0.85 in Canadian patients (Andermann et al, 1976). Parental consanguinity in the Italian patients is somewhat higher $(22 \%)$ than in the Canadian patients (14\%). Diabetes was present in $33 \%$ of Italian families and in $37 \%$ of Canadian families. We did not find any mention of familial pes cavus in the Canadian studies.

Some differences exist between the two countries regarding sex and age of onset of Friedreich's ataxia. Canadian patients showed a prevalence of females, while in the Italian patients the ratio between sexes was almost 1 . Age of onset in the Italian patients was higher than in the Canadian ones, particularly for females (Geoffroy et al, 1976). Such data was probably influenced by an erroneous evaluation of the onset of illness by the relatives of our patients. However, the mean duration of the disease at the time of study was fairly similar in the two sets. For the clinical rating scales, we have only personal data. We have already stressed that our scale of 13 items is a useful tool for the clinical evaluation of Friedreich's ataxia patients and could be used to test the clinical usefulness of new therapies for the disease.

The incidence of clinical signs agreed with the Canadian study (Geoffroy et al, 1976), however the same criteria were used to select the patients. Dysarthria, muscle weakness and nystagmus were not as frequent in our patients as in the Canadian ones. It is interesting to note (table 4) that pes cavus is sometimes unilateral.

In the manual ability tests, our Friedreich's ataxia patients had a marked disability similar to the disability found in Parkinson's disease or Huntington's chorea. Even though the clinical pictures were different, it was evident that dysmetria in the upper limbs was a cause of disability as severe as tremor in Parkinson's disease and hyperkinesia in Huntington's chorea. Considering the age difference between Friedreich's ataxia patients and patients with Parkinson's disease and Huntington's chorea, it appeared that Friedreich's ataxia patients were more severely disabled manually than Parkinsonian and choreic patients.

Thirteen percent of our patients had clinical diabetes and $26 \%$ chemical diabetes (total $=39 \%$ ). This is in agreement with the Canadian data that reported $18 \%$ of patients with clinical and $21 \%$ with chemical diabetes, that is a total of $39 \%$ in a group of 33 subjects (Shapcott et al, 1976).

Our data on serum cholesterol and triglycerides are also in good agreement with Canadian values. The total cholesterol is almost superimposable in controls and Friedreich's ataxia patients. Although still within normal limits, the mean level of total triglycerides is significantly increased in Friedreich's ataxia patients. The mean values reported by Huang et al (1978) were: cholesterol $=163.9$, triglycerides $=114.5$.
Gilbert's disease (unconjugated hyperbilirubinemia) was present in $20 \%$ of Italian patients. Thus, this feature is not specific to French-Canadian patients, though in the latter the percentage of hyperbilirubinemia was slightly higher $(9$ patients with total bilirubin $>1 \mathrm{mg} \%=27 \%$; Barbeau et al, 1976b).

Reports on monoamine metabolites in Friedreich's ataxia and related diseases are almost completely lacking. Johansson and Roos (1974) found reduced CSF HVA in three cases of cerebellar ataxia. Our data indicate a probable decrease in DA turnover in the central nervous system of patients with Friedreich's ataxia. In a previous paper we suggested that reduced CSF HVA is not an exclusive feature of Parkinson's disease, where it reaches low levels (Campanella et al, 1980). While in Parkinsonian patients the low HVA levels reflect a primary defect in DA turnover, it is possible that in other "degenerative" diseases such as Friedreich's ataxia, this biochemical abnormality is secondary to the involvement of other neurotransmitter pathways.

Cardiological abnormalities are less frequent in Italian than in Canadian ataxics (Malo et al, 1976; Gattiker et al, 1976). However, these abnormalities are of the same kind. EEG abnormalities are more frequent in Italian patients, though they do not differ from those found by Rémillard et al (1976). For a discussion of the EMG findings, we refer the reader to the paper by Caruso et al (1980).

In conclusion, our data showed that there were no major differences between the clinical pattern and laboratory investigations in Canadian and Italian patients with Friedreich's ataxia. This illness seems to be fairly frequent in Italy, where it forms a considerable part of the inherited spino-cerebellar degenerations.

\section{REFERENCES}

AJURIAGUERRA, J. DE. REGO, A. and TISSOT, R. (1963). Le réflexe oral et quelques activités orales dans les syndrômes démentiels du grand âge, Encéphale, 52, 189219.

ANDERMANN, E., REMILLARD, G.M., GOYER, C., BLITZER, L., ANDERMANN, F. and BARBEAU, A. (1976). Genetic and family studies in Friedreich's ataxia. Can. J. Neurol. Sci., 3, 287-301. 
BARBEAU, A. (1976a). Friedreich's ataxia 1976. An overview. Can. J. Neurol. Sci., 3, 389-397.

BARBEAU, A., BRETON, G., LEMIEUX, B. and BUTTERWORTH, R.F. (1976b). Bilirubin metabolism in Friedreich's ataxia. Preliminary investigation. Can. J. Neurol. Sci., 3, 365-372.

BUCHTAL, F. and ROSEFALCK, A. (1966). Evoked action potentials and conduction velocity in human sensory nerves. Brain Res., 3, 1-122.

CAMPANELLA, G., CARRIERI, P. and BUSCAINO, G.A. (1980). HVA E 5-HIAA liquorali nelle malattie extrapiramidali $e$ cerebellari. In press.

CANTER, G.J., DE LA TORRE, R, and MIER, M. (1961). A method for evaluating disability in patients with Parkinson's disease. J. Nerv. Ment. Dis., 133, 143-147.

CARRIERI, P., MANDARINI, A., OREFICE, G., CAMPANELLA, G. and BUSCAINO, G.A. (1976). Contributo allo studio del metabolismo centrale della dopamina e della serotonina. Dosaggio dei livelli liquorali di HVA e 5-HIAA col test al probenecid (modificato). Acta Neurol., 31, 558-564.

CARUSO, G., SANTORO, L., PERRETTI, A., SERLENGA, L., RAGNO, M., CRISCI, C., BARBIERI, F, and FILLA A. (1980). Friedreich's ataxia: Electrophysiological and histological aspects. Communication at the Swiss-Italian EMG Meeting, Capri, May 30, 1980.

DE FALCO, F.A., MANSI, D., VENTOLA, F., FILLA, A. and CAMPANELLA, G. (1979). Proposta di una scheda di rilevamento clinico delle eredo-atassie spinocerebellari. Acta Neurol., Quaderno XXXIX, 103-109.

DEMEURISSE, G., DEMOL, O. and GANTY, C. (1979). Semiological value of the palmomental reflex in vascular hemiplegia. Eur. Neurol., 18, 66-72.
FILla, A., CARlomagno, S., DI IORIO, G., FEDERICO, A., GUADAGNINO, $M$ and CAMPANELlA, G. (1980a). Studio epidemiologico delle eredo-atassie spinocerebellari in Campania. Proceedings of the Sixth Meeting of the Italian League to Combat Parkinson's Disease and Allied Disorders, Naples, October 26-27, 1979. In press.

FILla, A., POSTIGlione, A., RUBBA, P., PATTI, L., DE MICHELE, G., PALMA, V., BRESCIA MORRA, V. and CAMPANELLA, G. (1980b). Plasma lipoprotein concentration and erythrocyte membrane lipids in patients with Friedreich's ataxia. In press in Acta Neurol.

GATTIKER, H.F., DAVIGNON, A., BOZIO, A., BATLLE-DIAZ, J., GEOFFROY, G., LEMIEUX, B. and BARBEAU, A. (1976). Echocardiographic findings in Friedreich's ataxia. Can. J. Neurol. Sci., 3, 329-336.

GEOFFROY, G., BARBEAU, A., BRETON, G., LEMIEUX, G., AUBE, M. and LEGER, C. (1976). Clinical description and roentgenologic evaluation of patients with Friedreich's ataxia. Can. J. Neurol. Sci., 3, 279286.

GUDMUNDSSON, K.R. (1969). Prevalence and occurrence of some rare neurological diseases in Iceland. Acta Nerol. Scand., 45, 114-118.

HUANG, Y.S., NESTRUCK, A.C., BARBEAU, A., BOUCHARD, J.P. and DAVIGNON, J. (1978). Plasma lipids and lipoproteins in Friedreich's ataxia and familial spastic ataxia. Evidence for an abnormal composition of high density lipoproteins. Can. J. Neurol. Sci., 5, 149-156.

JOHANSSON, B., and ROOS, B.-E. (1974). 5Hydroxyindoleacetic acid and homovanillic acid in cerebrospinal fluid of patients with neurological diseases. Europ. Neurol., II, 37-45.
KORF, J., VAN PRAAG, H.M. and SEBENS, J.B. (197I). Effect of intravenously administered probenecid in humans on the levels of 5-hydroxyindoleacetic acid, homovanillic acid and 3-methoxy-4-hydroxyphenylglycol in cerebrospinal fluid. Biochem. Pharmacol.. 20, 659-668.

MALO, S., LATOUR, Y., COTE. M., GEOFFROY, G., LEMIEUX, B. and BARBEAU, A. (1976). Electrocardiographic and vectocardiographic findings in Friedreich's ataxia, Can. J. Neurol. Sci., 3, 323-328.

PEARCE, J. (1974). The extrapyramidal disorders of Alzheimer's disease. Europ. Neurol., 12, 94-103.

QUEBEC COOPERATIVE STUDY ON FRIEDREICH'S ATAXIA. PHASE ONE (1976). Can. J. Neurol. Sci., 3, 269-397.

QUEBEC COOPERATIVE STUDY OF FRIEDREICH'S ATAXIA. PHASE TWO, PART ONE (1978). Can. J. Neurol. Sci., 5, 53-165.

QUEBEC COOPERATIVE STUDY OF FRIEDREICH'S ATAXIA. PHASE TWO, PART TWO (1979). Can. J. Neurol. Sci., 6, 145319.

REMILLARD, G., ANDERMANN, F., BLITZER, L. and ANDERMANN, E. (1976). Electroencephalographic findings in Friedreich's ataxia. Can. J. Neurol. Sci., 3, 309312.

SHAPCOTT, D., MELANCON, S., BUTTERWORTH, R.F., KHOURY, K., COLLU, R., BRETON, G., GEOFFROY, G., LEMIEUX, B. and BARBEAU, A. (1976). Glucose and insulin metabolism in Friedreich's ataxia. Can. J. Neurol. Sci., 3, 361364.

SKRE, H. (1975). Friedreich's ataxia in Western Norway. Clin. Genet., 7, 287-298. 